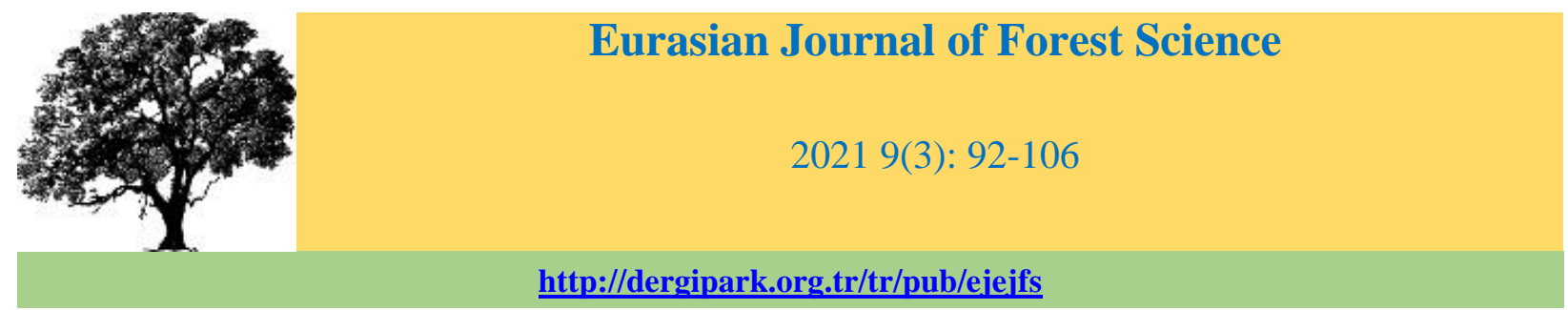

\title{
Doğu Anadolu Bölgesi'nin etnobotanik kullanımı olan bazı bitkilerin peyzaj düzenlemelerinde kullanım olanakları
}

\author{
Doğanay Yener ${ }^{1, *}$ (D), Betül Rüveyda Ay $\mathrm{Ak}^{2}(\mathrm{D}$ \\ 1, $\left.{ }^{*}\right)$ Istanbul Universitesi-Cerrahpaşa, Orman Fakültesi, Peyzaj Mimarlı̆̆ı Bölümü, İstanbul, Türkiye. \\ 2) İstanbul Universitesi-Cerrahpaşa, Lisansüstü Eğitim Enstitüsü, Peyzaj Mimarlı̆̆ı Yüksek Lisans Programı, \\ Istanbul, Türkiye \\ Sorumlu yazar: doganay@iuc.edu.tr
}

\begin{abstract}
Özet
Peyzaj düzenlemelerinin esas amacı insan ile doğa arasındaki bağı güçlendirerek, estetik, ekolojik, fonksiyonel ve aynı zamanda sürdürülebilir alanlar yaratmaktır. Bu süreç içerisinde sayısız renk, tekstür, form ve ölçüde bitki kullanarak dinamik ve estetik mekanlar oluşturmak mümkündür. Bu bitki çeşitliliği içerisinde doğal bitkiler; bulunduğu yörenin çevre koşullarına en iyi uyum sağlayan bitki türleri olarak sürdürülebilir peyzaj düzenlemelerinin başlıca elemanı olarak işlev görür. Ülkemiz sahip olduğu yaklaşık 12000 doğal bitki taksonu ile bitki çeşitliliği bakımından oldukça zengindir. $\mathrm{Bu}$ doğal bitki taksonlarının peyzaj düzenlemelerinde kullanımlarına yönelik çok sayıda çalışmaya rastlanırken; etnobotanik bağlamda ele alınmadıkları görülmektedir. Bu çalışmada Doğu Anadolu Bölgesi'ndeki insanların çeşitli amaçlarla faydalandığı bitkiler literatürden tespit edilerek; bunların yöredeki yaygın kullanımları irdelenmiştir. Etnobotanik kullanımları yaygın olan bu bitkilerin, aynı zamanda peyzaj düzenlemelerinde- kullanım olanakları değerlendirilerek önerilerde bulunulmuştur.
\end{abstract}

Anahtar Kelimeler: Etnobotanik, doğal bitkiler, peyzaj

Some plants with ethnobotanical use in the Eastern Anatolia Region and their usage possibilities in landscape designs

Abstract

The main purpose of landscape arrangements is to create aesthetic, ecological, functional and sustainable areas by strengthening the relation between human and nature. In this process, it is possible to create dynamic and aesthetic spaces by using plants having different color, texture, form and size. Within this diversity, natural plants which are the plant species that best adapt to the environmental conditions of the region and also acts as the main element of sustainable landscape designs. Our country is rich in terms of plant diversity with approximately 12000 natural plant taxa. While there are many studies about the use of these natural plant taxa in landscape designs. It is seen that they are not considered in the ethnobotanical context. In this study, by determining the ethnobotanical use of plants that people in the Eastern Anatolian Region benefit from in various ways; their widespread use in the region has been examined. Suggestions were made by evaluating the possibilities of using these plants in landscape designs, which are widely used in ethnobotany.

Key Words: Ethnobotany, natural plants, landscape 


\section{Giriş}

Günümüz dünyasında tükenmek üzere olan tüm kaynaklar, insanları alternatif yollar aramaya mecbur bırakmıştır. Var olan kaynakların korunması ve devamlılığı için insanoğlu planlamalarını sürdürülebilirlik üzerine taşımaya başlamıştır. Sürdürülebilirlik; imkanlardan hem faydalanabilmek hem de zarar vermeden devamlılığını sağlamak şeklinde tanımlanabilir.

Doğa temelli disiplinlerde de buradan yola çıarak yerel-doğal planlama ve tasarımlara doğru yönelim başlamıştır. Özellikle peyzaj düzenlemelerinde kullanılacak bitkilerin yörenin doğal bitki türlerinden seçilmesi, sürdürülebilir tasarımlar için önemli bir ilke olmuştur.

Tarih boyunca insanlar bitkileri gıda, yakacak, şifa vb. çeşitli amaçlarla kullanmışlardır. Etnobotanik kelimesinin kökü olan etno- insanların çalışılması, botanik de bitki bilimi anlamına gelir. Etnobotanik, farklı insan topluluklarındaki bitki-insan ilişkilerini ifade etmektedir (Tütenocaklı 2002, Heinrich 2004, Graham 2004, Kendir ve Güvenç 2010). Bu terim ilk kez 1895 y1lında, biyoloji profesörü John W. Harshberger tarafından kullanılmaya başlanmış olup basitçe "bitkilerin yerel halk tarafindan kullanımı" olarak tanımlanmıştır. Bu terimin bilim dünyasına girmesiyle etnobotanik çalışmalarda yeni bir çığır açılmış ve konu, halk da dâhil olmak üzere artık çok geniş bir kesimin ilgisini çekmiştir. Konuya yıllar içerisinde çeşitli bilim kolları katkısını sunmuştur. Bir başka tanımda ise etnobotanik; "bir yörede yaşayan insanların yöre bitkilerinden çeşitli amaçlarla yıllardır yararlanma" şeklinde ifade edilmektedir. Günümüzde sadece bitkilerin niçin kullanıldı̆̆ değil, aynı zamanda bitkilerin yetiştiği ortam şartlarının belirlenmesi konularına da odaklanmış olan etnobotanik terimi, farklı çalışma alanları ile birlikte değerlendirilmektedir (Kendir ve Güvenç 2010).

Bitkilerin etnobotanik yönden değerlendirilmeleri, insan ve doğanın karmaşık etkileşiminden doğan, tarihsel, coğrafi, kültürel, kültürler arası, ekonomik ve sosyal vb. yönleri olan bir olgu olarak ele alınmaktadır (Sõukand ve Kalle 2010). Yüzyıllar boyunca, doğadaki olağanüstü bitki çeşitliliği, bitkilerin kullanımıyla yakından bağlantılı kültürleri ve gelenekleri teşvik etmiş, sonuçta geniş ve çeşitli bir etnobotanik miras oluşturmuştur (Leto ve ark. 2012).

Bu çalışmanın amacı Doğu Anadolu Bölgesi’nde yaygın olarak kullanılan etnobotanik değeri yüksek bitkilerin peyzaj özelliklerini ortaya koymak ve bu bitkilerin farklı ölçeklerde geliştirilecek peyzaj düzenlemelerinde kullanımlarına yönelik değerlendirmelerde bulunmaktır. Bu amaç doğrultusunda Doğu Anadolu Bölgesi’nde yapılmış olan etnobotanik çalışmalar sistematik olarak analiz edilmiş ve değerlendirilmiştir. Tasarımsal özellikleri ve bulundukları habitatlar irdelenerek peyzaj düzenlemelerinde kullanım olanakları irdelenmiştir. Çalışmanın; peyzaj düzenlemelerinde etnobotanik bitkilerin kullanımına yönelik yeni bir bakış açısı getirmesi ve böylelikle ekolojik-kültürel mirasın korunması ve geliştirilmesine katkılar sunması beklenmektedir.

\section{Materyal}

Doğu Anadolu Bölgesi yüksek platolar ve dağlar sebebiyle ülkemizin en engebeli ve yükseltisi en fazla olan bölgesidir. Bölgenin ortalama yükseltisi 1500 m'nin üzerindedir. Doğu Anadolu Bölgesi'nde yükseltisi 5000 m'yi aşan ve ülkemizin en yüksek dağı olan Ağrı Dağı mevcuttur. Bölge floristik açıdan İran-Turan flora bölgesine dahildir. Bölgenin ormanlarını, kuzeydoğuda sarıçam, diğer kesimlerde özellikle yüksek dağlık ve platoluk alanlarda ise meşe ormanları oluşturmaktadır (Atalay 1994, Şengün ve Boyraz 2008). Kışın $-40^{\circ} \mathrm{C}$ 'ye düşen sıcaklık, yazın ise $20-25^{\circ} \mathrm{C}$ civarlarındadır. Yeryüzü şekillerinin elverişsizliği nedeniyle bazı kesimlerinde tarımın ve ulaşımın gelişmesine engel olmuştur. Ayrıca gerçek yüz ölçüm ile izdüşüm yüz ölçümü arasındaki farkın en yüksek olduğu bu bölgede toplam 14 tane il bulunmaktadır (Şengün ve Boyraz 2008) (Şekil 1). 


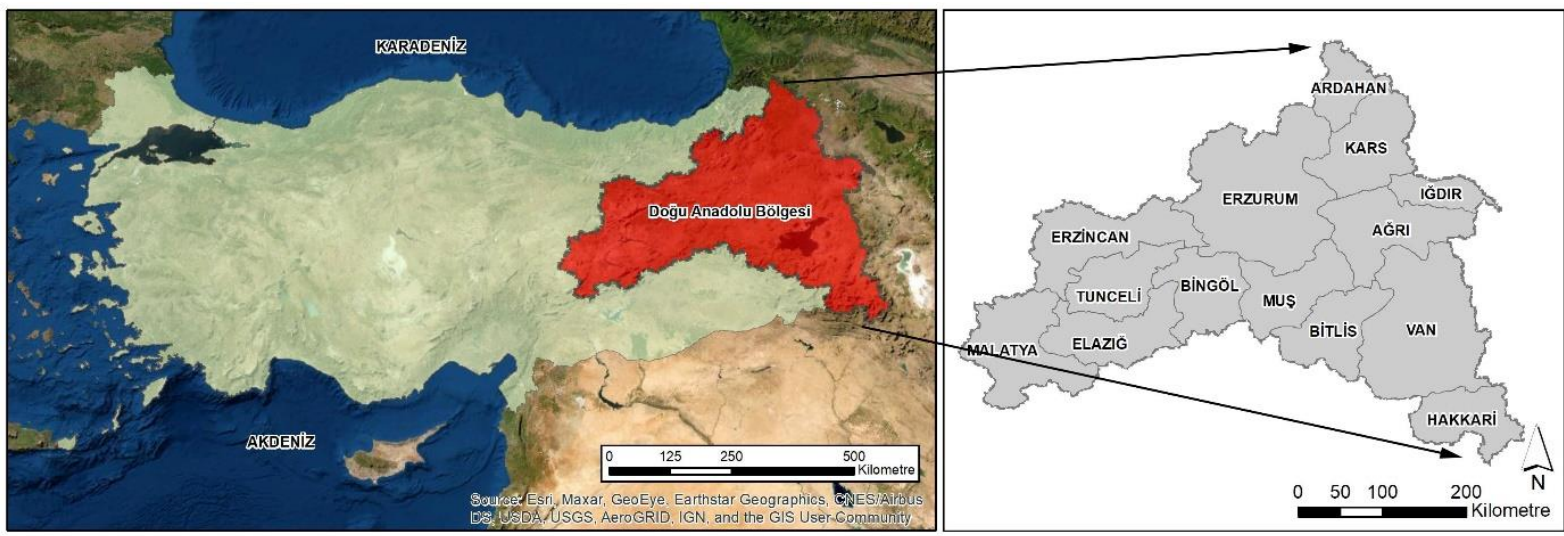

Şekil 1: Doğu Anadolu Bölgesi İller Haritas1

Araştırma materyalini Türkiye'nin Doğu Anadolu Bölgesi'nde yapılmış bazı etnobotanik çalışmalar oluşturmaktadır. Bu bağlamda öncelikle etnobotanik üzerine yapılıış çalışmalar "etnobotanik, ethnobotany ve ethnobotanical" anahtar kelimeleri, Ulusal Tez Merkezi, TR Dizin, Google Scholar ve ISI Web of Knowledge çevrimiçi veri tabanlarında taranarak elde ediliştir. Türkçe ya da İngilizce tam metnine ulaşılabilen ve de bitki tür listesi olan, 1975-2021 yılları arasında basılmış lisansüstü tez ya da makaleler bu çalışmada değerlendirmeye esas tutulmuştur. Elde edilen 162 çalışma içerisinden Doğu Anadolu Bölgesi'nin etnobotanik konulu bitkileri ile ilişkili elde edilen 59 adet çalışma değerlendirmeye esas alınmıştır. Bunlardan 47 tanesi makale ve kitap bölümü, 10 tanesi yüksek lisans tezi ve 2 tanesi ise doktora tezi şeklindedir.

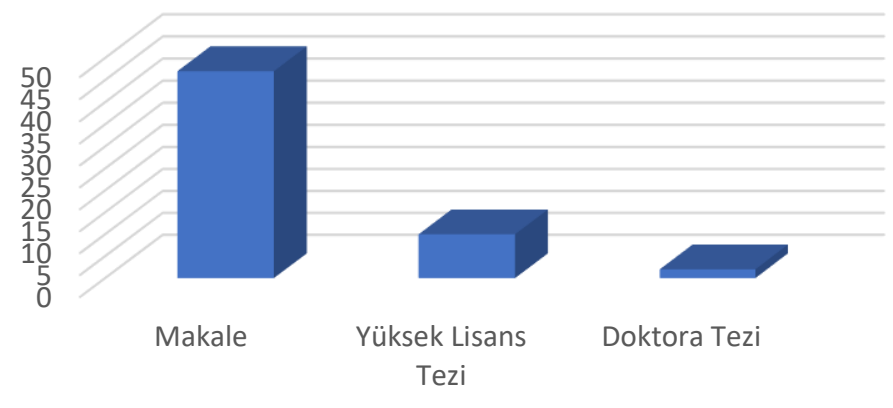

Şekil 2: Doğu Anadolu Bölgesi’nde Tespit Edilmiş Etnobotanik Konulu Çalışmaların Dağılımı

Doğu Anadolu Bölgesi'ndeki etnobotanik bitkilerin değerlendirdiği 59 çalışmanın illere göre dağılımlarına baktığımızda, Bingöl'e ait 7 makale (Kılıç 2016, Nadiroğlu ve Behçet 2018, Nadiroğlu et al. 2019, Polat et al. 2012, Polat et al. 2013, Polat et al. 2017, Polat, 2019) ve 1 yüksek lisans tezi (Nadiroğlu 2017) olmak üzere 8 çalışma; Elazığ'a ait 7 makale (Çakılcığlu ve Türkoğlu 2010, Çakılcıoğlu et al. 2010, Çakılcıoğlu et al. 2011, Hayta et al. 2014, Khatun et al. 2012, Kılış ve Bağcı 2013, Polat et al. 2015) ve 1 yüksek lisans tezi (Olgun 2019) olmak üzere toplamda 8 çalışma; Erzincan’ a ait 5 makale (Korkmaz et al. 2014, Korkmaz ve İlhan 2015, Korkmaz ve Karakuş 2015, Korkmaz et al. 2016a, Korkmaz et al. 2016b,) ve 2 yüksek lisans tezi (Alpaslan 2012, Tekin 2011) olmak üzere toplamda 7 çalışma; Van'a ait 5 makale (Dalar 2018, Dalar ve Mükemre 2020, Mükemre et al. 2015, Mükemre et al. 2016, Y1ldırım et al. 2008) ve 2 yüksek lisans tezi (Korkmaz 2018, Mükemre 2013) 
olmak üzere toplam 7 çalışma; Hakkari'ye ait 5 tane makale (Bulut et al. 2016, Görhan ve Öztürk 2021, Kaval et al. 2014, Kaval et al. 2015, Sirrı ve Sirrı 2020) ve 1 yüksek lisans tezi (Kaval 2011) olmak üzere toplamda 6 çalışma; Malatya'ya ait 3 makale (Tetik et al. 2013, Yeşil ve Akalın 2009, Yeşil ve Akalın 2016) ve 2 yüksek lisans tezi (Kolaç 2018, Tetik 2011) olmak üzere toplamda 5 çalışma; Erzurum'a ait 4 makale çalışması (Karakaya et al. 2019, Karakaya et al. 2020, Macit ve Köse 2015, Özgen et al. 2004); Tunceli'ye ait 1 makale (Doğan ve Tuzlac1 2015), 1 yüksek lisans tezi (Doğan 2008) ve 1 doktora tezi (Doğan 2014) olmak üzere toplamda 3 çalışma; Iğdır'a ait 1 makale (Çakır 2017) ve 1 doktora tezi (Altundağ 2009) olmak üzere 2 çalışma; Ağrı'ya ait 2 makale (Kadığlu et al. 2020, Dalar et al. 2018); Ardahan iline ait 1 makale (Akgül 2008); Bitlis iline ait 1 makale (Demir 2020) ve Kars iline ait 1 makale (Güneş ve Özhatay 2011) değerlendirmeye alınmıştır. Ayrıca Doğu Anadolu Bölgesi Allium türlerinin incelendiği 1 makale çalışması (Fırat 2015) ile yine Doğu Anadolu Bölgesi'ne ait etnobotanik çalışmaları konu alan 3 makale (Altundağ ve Öztürk 2011, Konczak et al. 2014, Polat et al., 2012) tespit edilip, değerlendirmeye alınmıştır (Şekil 3). Bunların dışında Doğu Anadolu Bölgesi'nde yer alan 14 ilden sadece Muş iline ait bitkilerin etnobotanik kullanımlarına yönelik bir çalışmaya rastlanmamıştır.

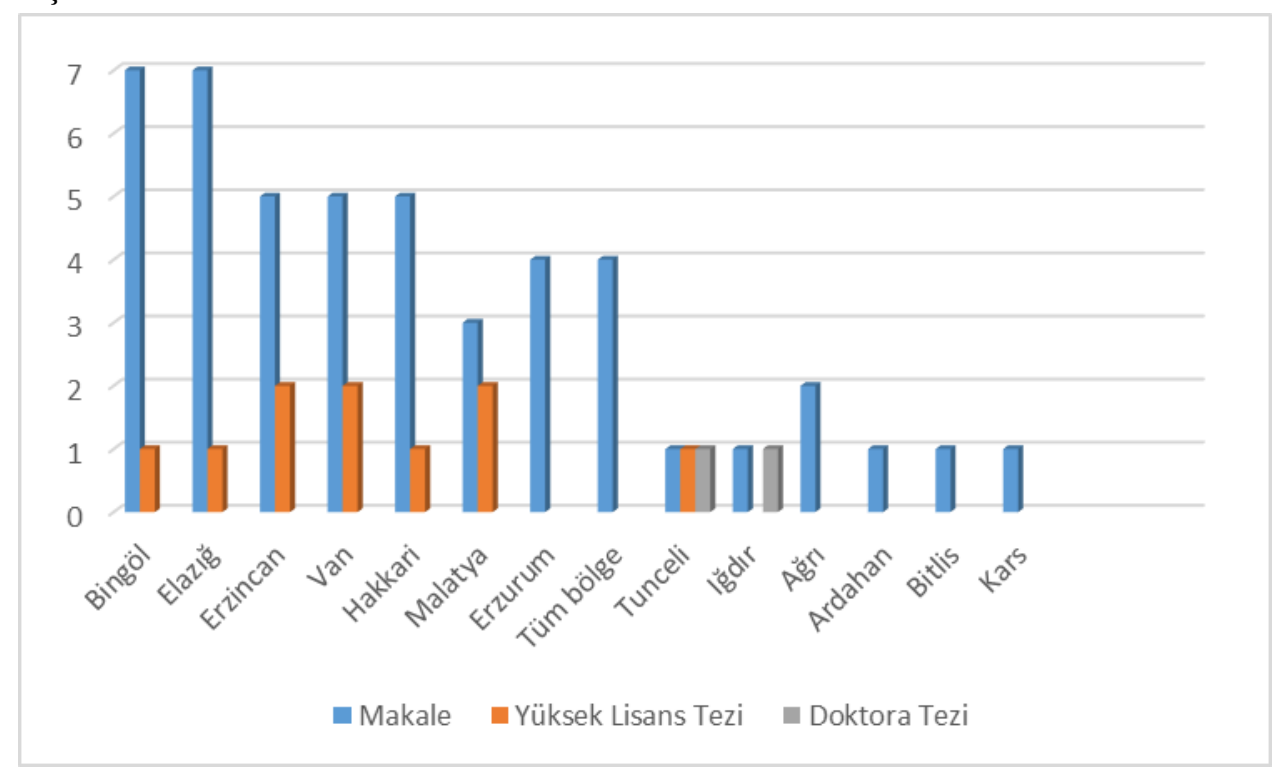

Şekil 3. Çalışmaların İllere Göre Dağılımı

\section{Metod}

Tespit edilen etnobotanik çalışmalardaki tür listelerinin topluca analizi ve değerlendirilebilmesi için bitki sosyolojisi araştırmalarında sıklıkla kullanılan TURBOVEG (Hennekens ve Schaminée 2001) veritabanı yönetim sisteminden yararlanılmıştır. Tüm çalışmaların veritabanına aktarılmasından sonra, "Doğu Anadolu Bölgesi'nden Etnobotanik Amaçlı Kullanılan Türler"in veritabanı hazır hale getirilmiştir. Oluşturulan veritabanı, türlerin sıklık ve illere göre bulunma durumlarının tespit edilmesi amacıyla JUICE 7.0 programına (Tichý ve Holt 2006) aktarılmış ve analiz edilmiştir. Bitkilerin tür ve familya bilgilerinde, "Flora of Turkey and East Eagean Islands" (Davis 1965-1985, Davis ve ark.1988, Güner ve ark. 2000) adlı eserler esas alınmıştır.

Analizler sonucunda bölge kapsamında en yaygın olarak saptanan ilk 38 takson belirlenmiştir. Bu bitkilerin etnobotanik özellikleri ile peyzaj düzenlemelerinde kullanım olanakları konuları olmak üzere iki aşamada değerlendirmeler yapılmıştır. İlk aşamada 38 taksonun etnobotanik kullanım alanları tespit 
etmek amacıyla 59 çalışma taranmış ve elde edilen bilgiler Excel ortamında oluşturulan tabloya sistematik bir şekilde aktarılmıştır (Tablo 1).

İkinci aşamada, "Flora of Turkey and East Eagean Islands" (Davis 1965-1985, Davis ve ark. 1988; Güner ve ark. 2000), "Flowers of Europe" (Polunin 1969), TUBIVES veritabanı ve "Türkiye Bitkileri”" kaynaklarından yararlanarak bu bitkilerin yapısı, ömrü, çiçek rengi, yaprak tekstürü, habitatları gibi fiziksel ve ekolojik özelliklerini kapsamlı bir şekilde ele alan bir tablo hazırlanmıştır (Tablo 2). Elde edilen veri setleri sonucunda bitkilerin tespit edilen etnobotanik ve yapısal özellikleri göz önünde tutularak peyzaj düzenlemelerinde kullanım olanakları ve alanları için öneriler sunulmuştur.

\section{Bulgular}

\section{Doğu Anadolu Bölgesi’nin Etnobotanik Yönden En Yaygın Bitkileri ve Kullanım Alanları}

Elde edilen veriler doğrultusunda Doğu Anadolu Bölgesi'nde toplam 1375 farklı bitki taksonunun etnobotanik amaçlı kullanıldığı sonucuna varılmıştır.

Şekil 4'teki grafik incelendiğinde Doğu Anadolu Bölgesi'nde yapılmış 59 etnobotanik konulu çalışmaların 30'unda kullanıldığı tespit edilen Urtica dioca ve Rheum ribes; yörenin en yaygın etnobotanik kullanıma sahip bitkileri olarak karşımıza çıkmaktadır. Ayrıca bu bitkilerin bölgedeki en yaygın etnobotanik kullanım alanının ise medikal amaçlı olduğu görülmektedir. Bölgede yapılmış olan etnobotanik çalışmalarda, seçilen en yaygın ilk 38 bitki arasında en az tekrar eden bitkiler ise; Crataegus orientalis var. orientalis, Amygdalus communis, Helichrysum plicatum subsp. plicatum, Ferula orientalis, Satureja hortensis, Vitis vinifera, Zea mays subsp. mays bitkileri olup, toplamda sadece 12 'şer çalışmada yer aldıkları belirlenmiştir.

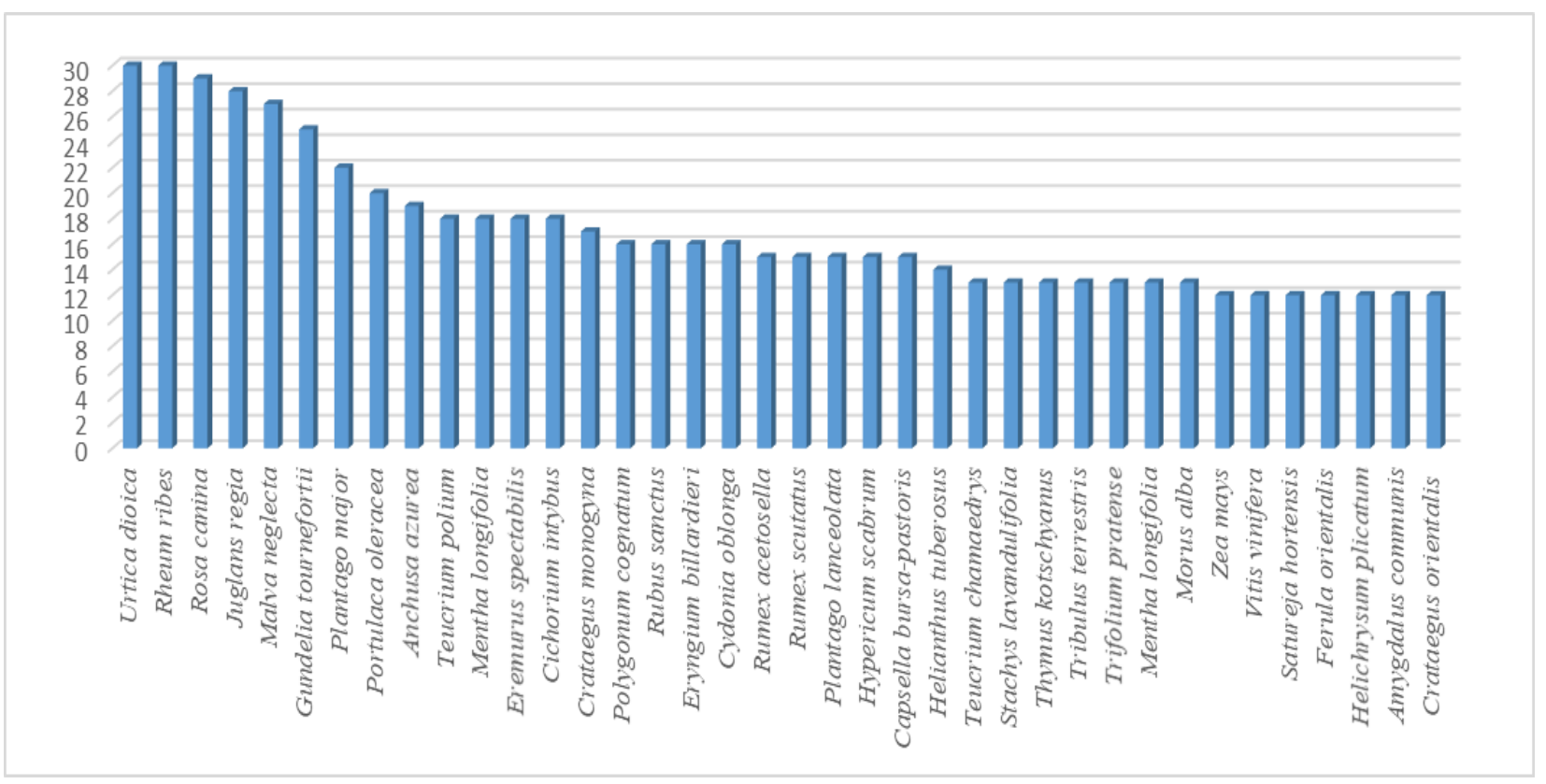

Şekil 4: Çalışmalarda En Fazla Tekrar Eden Bitkiler.

Değerlendirmeye alınan tüm bu bitkilerin Doğu Anadolu Bölgesi'nde medikal, gida, ekonomik, yakacak, baston, sanayi, boya, koku giderici, süs, sakız, kahve, hayvan yemi, böcek zehri, veterinerlik, 
temizlik, inanç, cilt bakımı, müzik aleti ya da yapıştırıcı gibi çeşitli etnobotanik kullanımlarının olduğu tespit edilmiştir (Tablo 1).

Tablo 1: Bitkilerin Etnobotanik Kullanım Şekilleri

\begin{tabular}{|c|c|c|}
\hline Bitki Adı & Familya & Etnobotanik Kullanım Şekilleri \\
\hline Urtica dioica & Urticaceae & Medikal, Gıda, Saç Bakımı. \\
\hline Rheum ribes & Polygonaceae & Medikal, Gida, Ekonomik. \\
\hline Rosa canina & Rosaceae & Medikal, Gida. \\
\hline Juglans regia & Juglandaceae & $\begin{array}{l}\text { Medikal, Gıda, Saç Bakımı, Yakacak, Sanayi, } \\
\text { Boya, Koku giderici, Dibek. }\end{array}$ \\
\hline Malva neglecta & Malvaceae & Medikal, Gida. \\
\hline Gundelia tournefortii var. tournefortii & Asteraceae & Medikal, Ekonomik, Sakız, Kahve, Hayvan Yemi. \\
\hline Plantago major subsp. major & Plantaginaceae & Medikal, Gıda. \\
\hline Portulaca oleracea & Portulacaceae & Medikal, Gida, Ekonomik. \\
\hline Anchusa azurea var. azurea & Boraginaceae & Medikal, Gıda, Boya. \\
\hline Teucrium polium & Lamiaceae & Medikal, Gıda, Hayvan İlacı. \\
\hline $\begin{array}{l}\text { Mentha longifolia subsp. typhoides } \\
\text { typhoides }\end{array}$ & Lamiaceae & Medikal, Gida. \\
\hline Eremurus spectabilis & Liliaceae & Medikal, Gıda, Ekonomik, Yapıştırıcı. \\
\hline Cichorium intybus & Asteraceae & Medikal, Gida, Hayvan Yemi. \\
\hline Crataegus monogyna subsp. monogyna & Rosaceae & Medikal, Gıda, Yakacak. \\
\hline Polygonum cognatum & Polygonaceae & Medikal, Gida. \\
\hline Rubus sanctus & Rosaceae & Medikal, Gida. \\
\hline Eryngium billardieri & Apiaceae & Medikal, Gida, Hayvan Yemi. \\
\hline Cydonia oblonga & Rosaceae & Medikal, Gıda, Yakacak, İnanış, Cilt Bakımı. \\
\hline Rumex acetosella & Polygonaceae & Medikal, Gida. \\
\hline Rumex scutatus & Polygonaceae & Medikal, Gida, Boya. \\
\hline Plantago lanceolata & Plantaginaceae & Medikal. \\
\hline Hypericum scabrum & Guttiferae & Medikal, Ekonomik. \\
\hline Capsella bursa-pastoris & Brassicaceae & Medikal, Gida, Hayvan Yemi. \\
\hline Helianthus tuberosus & Asteraceae & Medikal, Gida. \\
\hline Teucrium chamaedrys subsp. sinuatum & Lamiaceae & Medikal, Gida. \\
\hline Stachys lavandulifolia var. lavandulifolia & Lamiaceae & Medikal, Gıda, Hayvan Yemi. \\
\hline Thymus kotschyanus var. kotschyanus & Lamiaceae & Medikal, Gida. \\
\hline Tribulus terrestris & Zygophyllaceae & Medikal. \\
\hline Trifolium pratense var. pratense & Fabaceae & Medikal, Gıda, Hayvan Yemi, Böcek İlacı-Zehir. \\
\hline Mentha longifolia subsp. longifolia & Lamiaceae & Medikal, G1da. \\
\hline Morus alba & Moraceae & Medikal, Gıda, Yakacak, Müzik Aleti. \\
\hline Zea mays subsp. mays & Poaceae & Medikal, Gida, Hayvan Yemi. \\
\hline Vitis vinifera & Vitaceae & Medikal, Gıda, Ekonomik. \\
\hline Satureja hortensis & Lamiaceae & Medikal, Gıda, Temizlik. \\
\hline Ferula orientalis & Apiaceae & $\begin{array}{l}\text { Medikal, Gıda, Hayvan Yemi, Böcek İlacı-Zehir, } \\
\text { Hayvan İlacı. }\end{array}$ \\
\hline Helichrysum plicatum subsp. plicatum & Asteraceae & Medikal, Süs. \\
\hline Amygdalus communis & Rosaceae & Medikal, Gıda, Yakacak. \\
\hline Crataegus orientalis var. orientalis & Rosaceae & Medikal, G1da, Yakacak, Baston. \\
\hline
\end{tabular}


Bitkilerin etnobotanik kullanımları incelendiğinde 38 bitkinin tamamının da Doğu Anadolu Bölgesi'nde medikal amaçlı kullanımının mevcut olduğu görülmektedir. Plantago lanceolata, Hypericum scabrum, Tribulus terrestris ve Helichrysum plicatum subsp. plicatum taksonları dışında 34 bitkinin ise gıda olarak tüketimi mevcuttur. Medikal ve gıda kullanımından sonra her bitkide farklı kullanımların ön plana çıktığı dikkat çekmektedir. Örneğin Juglans regia bitkisi için medikal ve gida amaçl1 kullanımından sonra en yaygın diğer kullanım şekli boya olarak kullanımıdır. Amygdalus communis ve Crataegus orientalis var. orientalis bitkilerinin ise medikal ve gıda kullanımlarından sonra öne çıkan özelliği ise yakacak olarak kullanılabilmesidir (Tablo 1).

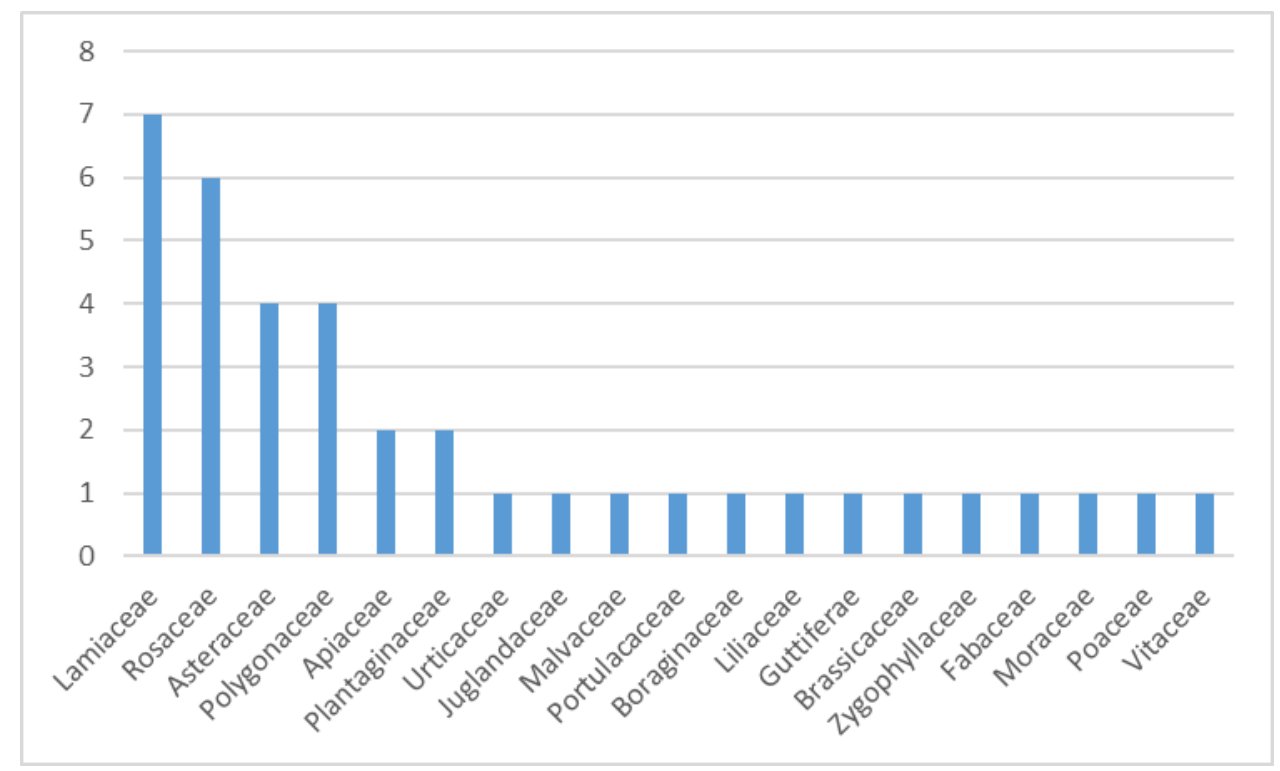

Şekil 5. Familyalara göre dağılımları

Şekil 5'te Doğu Anadolu Bölgesi en yaygın etnobotanik kullanımı olan bitkilerin familyalara göre dağılımları verilmiştir. Buna göre bölgenin etnobotanik kullanıma sahip bitkilerinin en çok yer aldığı familyalar sirasiyla Lamiacaeae, Rosaceae, Asteraceae ve Polygonaceae, Apiaceae ve Plantaginaceae olup, geri kalan familyalar ise tek bitki taksonu ile temsil edilmektedir.

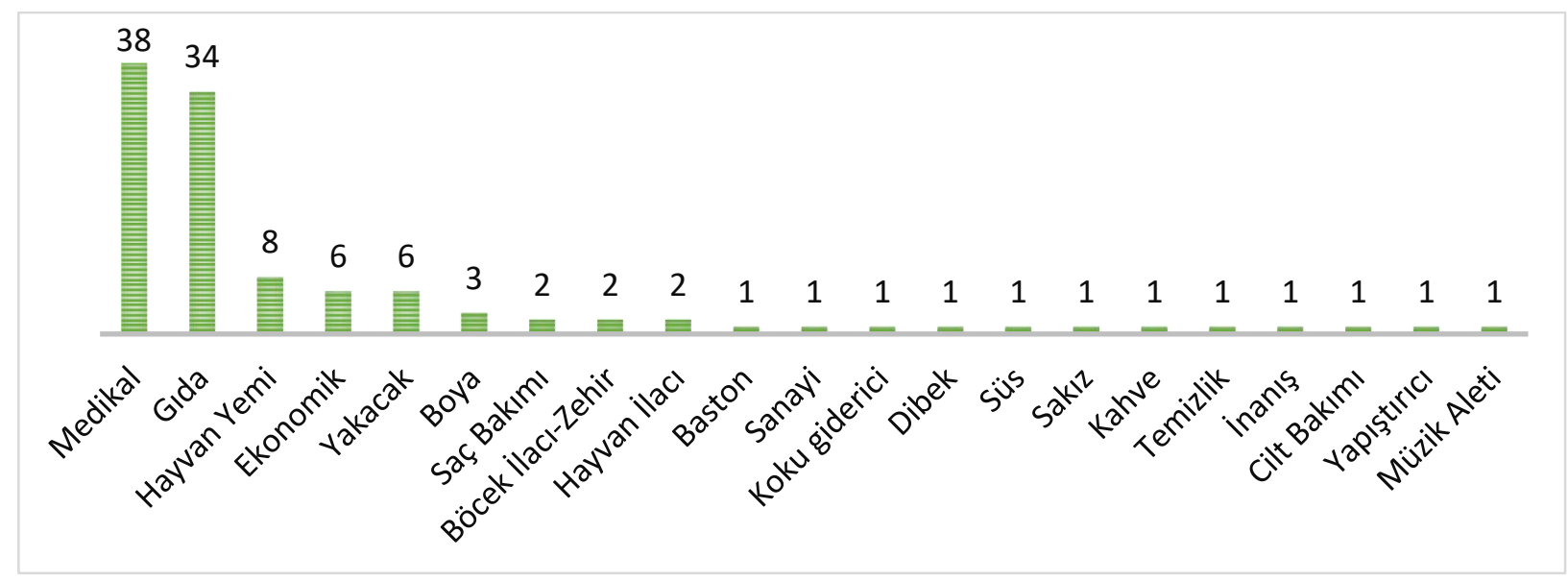


Şekil 6: Bitkilerin Etnobotanik Kullanımları.

Yöredeki etnobotanik kullanımlar incelendiğinde medikal ve gıda olarak kullanımlarının dışında; 8 bitkinin hayvan yemi olarak kullanıldığı, 6 bitkinin ekonomik amaçlı kullanımı, 6 bitkinin yakacak olarak kullanıldığı kaydedilmiştir. Baston, dibek, yapıştırıcı, müzik aleti gibi çeşitli gereçler için kullanılan 1'er bitki olduğu; bunun yanı sıra sakız veya kahve olarak tüketilen bitkiler olduğu da görülmektedir. Ayrıca temizlik, inanış, saç bakımı, cilt bakımı, böcek zehri, boya ve hayvan ilacı olarak da kullanılan bitkiler mevcuttur (Şekil 6).

\section{Doğu Anadolu Bölgesi’nin En Yaygın Etnobotanik Kullanımı Olan Bitkilerinin Tasarım Özellikleri}

Tablo 2: Bitkilerin Tasarım Özellikleri

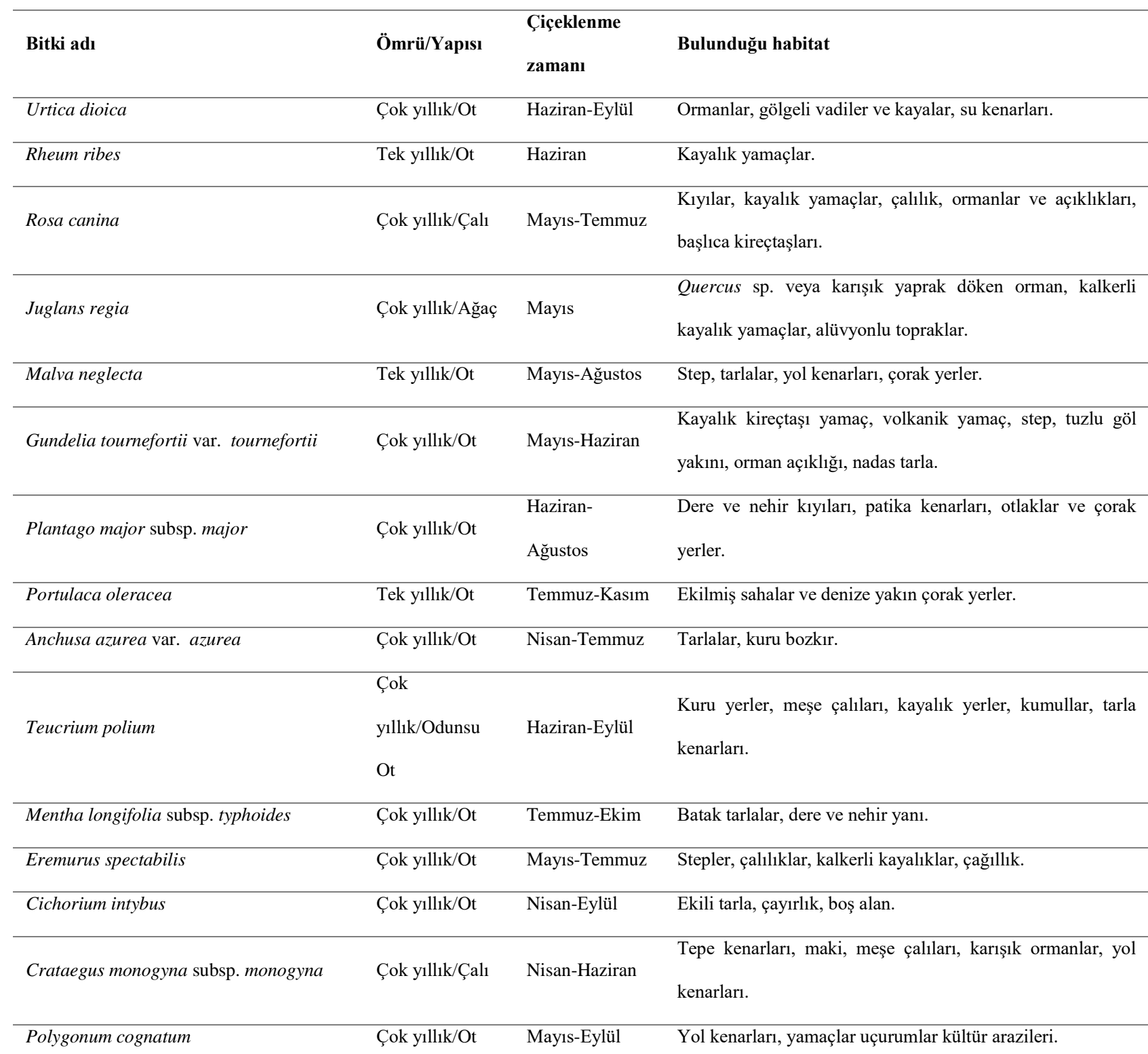


EJFS-Doğu Anadolu Bölgesi’nin etnobotanik kullanımı olan bazı bitkilerin peyzaj düzenlemelerinde kullanım olanaklarl-Yener ve Ay Ak 2021

\begin{tabular}{|c|c|c|c|}
\hline Rubus sanctus & Çok yıllık/Çalı & $\begin{array}{l}\text { Haziran- } \\
\text { Ağustos }\end{array}$ & $\begin{array}{l}\text { Seyrek çalılık, kayalık yerler, nehir kıyıları, sabit kumullar, } \\
\text { ovalar, çorak kıyılar. }\end{array}$ \\
\hline Eryngium billardieri & Çok yıllık/Ot & $\begin{array}{l}\text { Temmuz- } \\
\text { Ağustos }\end{array}$ & Kayalık yamaçlar, stepler, nadas tarlalar. \\
\hline Cydonia oblonga & Çok yillık/Çalı & Mayıs-Haziran & Ormanlar ve çalılar. \\
\hline Rumex acetosella & Çok yıllık/Ot & Mayıs-Ağustos & Tarlalar, kıyılar, çorak yerler. \\
\hline Rumex scutatus & Çok yıllık/Ot & $\begin{array}{l}\text { Haziran- } \\
\text { Ağustos }\end{array}$ & Yamaçlar, çağıllıklar, tepe kenarları, tarlalar. \\
\hline Plantago lanceolata & Çok yıllık/Ot & Nisan-Ekim & $\begin{array}{l}\text { Deniz kıyıları, kumluk plajlar, çayırlık, bataklık yerler, maki, } \\
\text { dere kıyıları. }\end{array}$ \\
\hline Hypericum scabrum & Çok yıllık/Ot & May1s-Ağustos & Kuru kayalık yamaçlar, açık koruluklar veya step. \\
\hline Capsella bursa-pastoris & Tek yıllık/Ot & Ocak-Aralık & Ekili alan, boş alan. \\
\hline Helianthus tuberosus & Çok yıllık/Ot & Bilinmiyor & Kültür bitkisi. \\
\hline Teucrium chamaedrys subsp. sinuatum & Çok yıllık/Ot & $\begin{array}{l}\text { Haziran- } \\
\text { Ağustos }\end{array}$ & Volkanik ve kireçtaşı yamaçlar, bozkır yol ve tarla kenarları. \\
\hline
\end{tabular}

Çok

Stachys lavandulifolia var. lavandulifolia $\quad$ yıllık/Odunsu $\quad$ Mayıs-Ağustos $\quad$ Kalkerli volkanik kaya yamaçları.

Ot

\begin{tabular}{|c|c|c|c|}
\hline Thymus kotschyanus var. kotschyanus & Çok y1llık/Çalı & Mayis-Temmuz & Çıplak dağ yamaçları. \\
\hline Tribulus terrestris & Tek yıllık/Ot & Haziran-Eylül & Açık ve kumlu yerler, nadas tarlaları. \\
\hline Trifolium pratense var. pratense & Çok yıllık/Ot & Mayıs-Eylül & Çayırlık, yol kenarları, orman açıklıkları. \\
\hline Mentha longifolia subsp. longifolia & Çok yıllık/Ot & $\begin{array}{l}\text { Haziran- } \\
\text { Ağustos }\end{array}$ & Dere kenarları ve bataklıklar. \\
\hline Morus alba & Çok yıllık/Ağaç & Mayıs & Kültür bitkisi. \\
\hline Zea mays subsp. mays & Tek yıllık/Ot & Haziran-Ekim & Kültür, terkedilmiş tarlalar içinde. \\
\hline Vitis vinifera & Çok yıllık/Çalı & Bilinmiyor & Kültür bitkisi. \\
\hline Satureja hortensis & Tek yıllık/Ot & Haziran-Eylül & $\begin{array}{l}\text { Kayalık ve aşınmış yamaçlar, çakıllı yerler, kıyılardaki } \\
\text { gevşek kumullar, nadas. }\end{array}$ \\
\hline Ferula orientalis & Çok yıllık/Ot & Mayıs-Haziran & Kayalık yamaçlar. \\
\hline Helichrysum plicatum subsp. plicatum & Çok yıllık/Ot & $\begin{array}{l}\text { Haziran- } \\
\text { Ağustos }\end{array}$ & $\begin{array}{l}\text { Pinus nigra ve Abies cilicica orman açıklığı, çalılık, kayalık } \\
\text { yamaç. }\end{array}$ \\
\hline Amygdalus communis & Çok yıllık/Ağaç & Mart-Nisan & $\begin{array}{l}\text { Doğal, kuru yamaçlar, kalkerli geçitler, çalı ve meşe } \\
\text { ormanlıkları. }\end{array}$ \\
\hline Crataegus orientalis var. orientalis & Çok yıllık/Çalı & Mayıs-Temmuz & Kayalık yerler, ormanlar. \\
\hline
\end{tabular}


Yöredeki etnobotanik amaçlı en yaygın kullanılan bitkilerin \%72'sinin çok yıllık, \%18'inin ise tek yıllık olduğu görülmektedir. Yine aynı şekilde \%32'si odunsu yapıda (odunsu ot-çalı-ağaç), \%68'i ise otsu yapıdadır. Peyzaj düzenlemelerinde bitkilerin en önemli görsel özelliklerinden birinin çiçek renkleri olduğu bilinmektedir. Yöredeki etnobotanik amaçlı en yaygın kullanılan bitkilerin çiçek renkleri değerlendirildiğinde; en fazla sayıda beyaz renk çiçeklenen bitkilerin olduğu (\%35), onu takiben sarı renk çiçeklenenler (\%24) ve pembe renk çiçeklenenlerin (\%22) geldiği görülmektedir. Yine bitkilerin en önemli çiçek özelliklerinden biri ne zaman çiçeklendikleri, bir diğeri de ne kadar süre çiçekli kaldıklarıdır. Buna göre çalışmada Ocak ve Mart aylarında çiçeklenen 1'er tane bitki taksonu yer alırken, büyük bir çoğunluğunun Mayıs (\%40) ve Haziran (\%26) aylarında çiçeklendiği görülmektedir. Çiçekli kalma zamanları değerlendirildiğinde ise; Capsella bursa-pastoris bitkisinin 12 ay, Plantago lanceolata bitkisinin 7 ay ve Cichorium intybus'un 6 ay çiçekli kalıyor olmaları dikkat çekmektedir. Büyük çoğunluğu ise 3 ay (\%32) ve 4 ay (\%24) çiçekli kalmaktadır (Tablo 2).

Bitkilerin tasarım kriterleri göz önüne alınarak ve bulundukları habitatlar değerlendirildiğinde 3 farklı alanda kullanımları ön plana çıkmaktadır. Bu alanlar içerisinde özellikle Doğu Anadolu Bölgesi'nin arazi şekillerinden ve ikliminden kaynaklı olarak kayalık habitatlar ile sucul habitatlar sayıca fazladır. Ayrıca yine bölgenin ekstrem koşullarından ötürü yol kenarı bitkileri de yine başlıca habitat sınıflarından birini oluşturmaktadır.

\section{Tartışma ve Sonuç}

Sahip olduğu iklim ve arazi yapısı nedeniyle oldukça zengin bitki varlığına sahip Doğu Anadolu Bölgesi’nin etnobotanik kullanıma sahip bitkiler açısından da dikkat çekici bir özellik sergilediği görülmektedir. Yapılan çalışma sonucunda yörede toplam 1375 farklı bitki taksonunun etnobotanik amaçlı kullanıldığı, yapılan çalışmalar ile ortaya konmuştur. Bölgedeki en fazla etnobotanik kullanımların ise medikal ve gıda amaçlı olduğu görülmüştür. Benzer şekilde Altındağ (2009)'un "Iğdır ilinin doğal bitkilerinin halk tarafından kullanımı" başlıklı doktora tez çalışması sonucunda farklı kullanışlara sahip 292 doğal bitki taksonu saptanmıştır. Bunlar içerisinde en yaygın olarak 162 takson ile medikal ve 143 takson ile gıda amaçlı kullanımın geldiği ifade edilmiştir. Nadiroğlu (2017)'nin Bingöl iline bağlı Karlıova ilçesi ve köylerinde gerçekleştirdiği yükssek lisans tez çalışmasında ise toplamda etnobotanik kullanıma sahip 121 bitki taksonu ve bu bitkilere ait 280 yöresel kullanım şekli tespit edilmiştir. Kolaç (2018)'in Malatya ilinin Yeşilyurt ilçesine bağlı Konak beldesinin geleneksel olarak kullanılan halk ilaçlarının belirlenmesi amacıyla yaptığı çalışmada toplamda 86 taksonun halk ilacı kapsamında değerlendirildiği sonucuna varılmıştır. Polat et al. (2012)'nin Doğu Anadolu bölgesinde yapılmış etnobotanik araştırmaların değerlendirildiği çalışmalarında toplamda 132 etnobotanik içerikli çalışma ile 15 tez tespit edilmiştir. Bölgede yapılmış olan çalışmalarda tıbbi bitkiler, gıda bitkileri ve boya bitkileri ile ilgili en fazla çalışmanın yer aldığı sonucuna varılmıştır.

$\mathrm{Bu}$ çalışmada yöre halkı tarafindan çok yönlü kullanımlara sahip olduğu görülen bu bitkilerin aynı zamanda peyzaj düzenlemelerinde farklı kullanım alanları için uygunluk durumları değerlendirilmiştir. İncelenen ve analizleri yapılan tüm veriler 1şı̆̆ında Doğu Anadolu Bölgesi'nde yöre halkının etnobotanik özelliklerinden dolayı yetiştirip çeşitli alanlarda kullanmayı tercih ettiği bitkilerin, tasarım potansiyelleri araştırıldığında peyzaj düzenlemelerinde başta doğala yakın bahçeler olmak üzere çeşitli amaçlarla kullanılabileceği görülmüştür. Çalışmada; büyük çoğunluğunun medikal amaçlı kullanımının olduğu bilinen bu bitkilerin habitatları, yaprak özellikleri, çiçek özellikleri, yapıları ve ömürleri gibi özellikleriyle peyzaj düzenlemelerinde kullanımları irdelenmiştir. 
Helichrysum plicatum subsp. plicatum bitkisinin yörede kullanımı yoğunlukla medikal amaçlıyken yalnızca 1 çalışmada süs amaçlı kullanıldığı kaydedilmiştir. Çok yıllık bir otsu olan bu bitki 40 santimetreye kadar boylanabildiği ve doğal habitatlarından birinin ise "kayalıklar" olduğu da görülmektedir. Bu bitki, yöre kullanımlarının yanı sıra kaya bahçelerinde ya da kurakçıl peyzaj tasarımlarında da değerlendirilebilir. Gri-yeşil, ince tekstürlü ve şerit şeklindeki yaprakları ve sahip olduğu sarı çiçekleri ile özellikle kaya bahçeleri gibi bir ortamda dikkatleri üzerine çekecektir. Ayrıca sağlayacağı güçlü kontrast özelliği ile tasarımlarda değerlendirilebilir. Rubus sanctus, çok yıllık yapısı ve çalı formuyla 1-2 metreye kadar boylanabilen bir bitkidir. Meyve özelliği ile ön plana çıan bu bitkinin yörede genellikle medikal ve gıda amaçlı kullanımının olduğu görülmektedir. Habitatları incelendiğinde ise, kayalık ve sulak alanlarda da doğal olarak yetişebildiği görülmektedir. Pembe çiçekleriyle de dikkat çeken bu bitkiye tasarımlarda daha sık yer verilebilir. Hem su kenarına hem kayalık alanlara uyum sağlayabilen bir diğer bitki ise Satureja hortensis'dir. Tek ylllık olan bitki yaklaşık 30 santimetreye kadar uzayan, ince tekstürlü yeşil şerit yaprakları vardır. Ayrıca aromatik kokuya da sahip bu bitki yörede en fazla medikal amaçlı kullanılmakla beraber gıda ve temizlik amacıyla da kullanılmaktadır. Özellikle kaya bahçelerinde ve çiçek parterlerinde kullanılabilecek ideal bir türdür. Malva neglecta çekici mor renk çiçekleriyle otsu çiçek parterlerinde değerlendirilebilir. Yine aynı şekilde mavi renk çekici çiçeklerini senenin büyük bir çoğunluğunda sergileyen Cichorium intybus peyzaj düzenlemelerinde özellikle çiçek parterlerinde, kaya bahçelerinde, çim alanlarda ve grup bitkilendirmelerinde tercih edilebilir. Mentha longifolia ise sahip olduğu koku ve gösterişli mor renk çiçek kurulları ile özellikle aromatik bahçelerde değerlendirilebilir.

Doğu Anadolu Bölgesi’nin otsu, çalı ve ağaç formunda; çok veya tek yıllık; farklı çiçek ve yaprak özelliklerine sahip oldukça zengin etnobotanik bitki çeşitliliğine sahiptir. Yapılan çalışmalar değerlendirildiğinde yörede etnobotanik amaçlı kullanılan doğal bitkilerinin büyük bir çoğunluğunun peyzaj düzenlemelerinde kullanılabilme potansiyelinin olduğu görülmektedir. Böylelikle bu bitkilerin kullanımları yaygınlaştırılarak, gelecek kuşaklara aktarımı sağlanacaktır. Bu sayede aynı zamanda ekolojik-kültürel mirasın korunmasına ve gelişmesine yönelik büyük katkılar elde edilecektir.

\section{Teșekkür}

Verilerin düzenlenme aşamasındaki katkılarından ötürü Araş. Gör. Selim Bayraktar’a teşekkür ederiz.

\section{Kaynaklar}

Akgül, G. (2008). Çıldır (Ardahan) ve Çevresinde Bulunan Bazı Doğal Bitkilerin Yerel Adları ve Etnobotanik Özellikleri, OT Sistematik Botanik Dergisi, 14, 1, 75-88.

Atalay, İ. (1994). Türkiye Vejetasyon Coğrafyası, Dokuz Eylül Üniversitesi, Buca Eğitim Fakültesi, İzmir.

Atalay, İ., Mortan, K. (2006). Türkiye Bölgesel Coğrafyası, İnkılap Kitabevi, İstanbul.

Alpaslan, Z. (2012). Ergan Dağı (Erzincan)'nın Etnobotanik Özellikleri. Erzincan: Erzincan Üniversitesi Fen Bilimleri Enstitüsü.

Altundağ, E. (2009). Iğdır İlinin (Doğu Anadolu Bölgesi) Doğal Bitkilerinin Halk Tarafından Kullanımı. Doktora Tezi, İstanbul Üniversitesi, Sağlık Bilimleri Enstitüsü.

Altundağ, E., Öztürk, M. (2011). Ethnomedicinal Studies on the Plant Resources of East Anatolia, Turkey, Procedia- Social and Behavioral Sciences, 19, 756-777.

Bulut, G., Biçer, M., Tuzlacı, E. (2016). The folk medicinal plants of Yüksekova (Hakkari-Turkey). Journal of Pharmacy of Istanbul University, 46(2), pp. 115-124. 
Çakılcığlu , U., Khatun, S., Türkoğlu, İ., Hayta , Ş. (2011). Ethnopharmacological survey of medicinal plants in Maden (Elazig-Turkey). Journal of Ethnopharmacology, pp. 469-485.

Çakılcığlu, U., Şengün, M. T., Türkoğlu, İ. (2010). An ethnobotanical survey of medicinal plants of Yazıkonak and Yurtbası Districts of Elazığ Province, Turkey. Journal of Medicinal Plants Research, 4(7), pp. 567-572.

Çakılcığlu, U., Türkoğlu, İ. (2010). An ethnobotanical survey of medicinal plants in Sivrice (Elazıg-Turkey). Journal of Ethnopharmacology, Cilt 132, pp. 165-175.

Çakır, E. A. (2017). Traditional knowledge of wild edible plants of Iğdır Province (East Anatolia, Turkey). Acta Societatis Botanicorum Poloniae, 86(4).

Dalar, A., Mükemre, M., Ünal, M., Özgökçe, F. (2018). Traditional medicinal plants of Ağrı Province, Turkey. Journal of Ethnopharmacology, Issue 226, pp. 56-72.

Dalar, A. (2018). Plant Taxa Used in the Treatment of Diabetes in Van Province, Turkey, International Journal of Secondary Metabolite, 5, 3, 171-185.

Dalar, A. ve Mükemre, M. (2020). Traditional Medicinal Plants of Van Province, Eastern Anatolia, In book: Anatolia: Past, Present and Future PerspectivesPublisher: Nova Science Publishers.

Davis, P. (1965-1985). Flora of Turkey and East Aegean Islands. Edinburg: Vol:1-9 University Press.

Davis, P., Mill, R. R. ve Kit Tan. (1988). Flora of Turkey and the East Aegean Islands (Supplement). Edinburgh: Volume 10, University Press.

Demir, İ. (2020). An Ethnobotanical Study of Medicinal Plants Used in Hizan District (Bitlis-Turkey), Yüzüncü Yıl Üniversitesi Tarım Bilimleri Dergisi, Cilt 30, Sayı 4, 732-741.

Doğan, A. (2008). Ovacık (Tunceli) Yöresinin Geleneksel Halk İlacı Olarak Kullanılan Bitkileri. İstanbul: T.C. Marmara Üniversitesi Sağık Bilimleri Enstitüsü.

Doğan, A. (2014). Pertek (Tunceli) Yöresinde Etnobotanik Araştırmalar. İstanbul: Marmara Üniversitesi Sağlık Bilimleri Enstitüsü.

Doğan, A., Tuzlacı, E. (2015). Wild Edible Plants of Pertek (Tunceli-Turkey). Marmara Pharmaceutical Journal, Cilt 19, pp. 126-135.

Firat, M. (2015). The Ethnobotanical Usage of Some East Anatolian (Turkey) Allium L. Species. Manas Journal of Agriculture and Life Science, 5(1), pp. 80-86.

Güner, A., Özhatay, N., Ekim, T., Başer, H.C., Hedge, I. (2000). Flora of Turkey and East Aegean Islands. (Supplement 2). Edinburg: Vol:11, University Press.

Görhan, K.Ö. ve Öztürk, F. (2021). Ethnopharmacological Survey of Medicinal and Foods Plants in Derecik (Hakkari-Turkey), Indian Journal of Traditional Knowledge, Vol 20(2), 416-425.

Güneş, F. ve Özhatay, N. (2011). An Ethnobotanical Study From Kars (Eastern) Turkey, Biological Diversity and Conservation, 4/1, 30-41.

Graham, L. E., Graham, J. M., Wilcow, L. W. (2004). Bitki Biyolojisi, Çeviri Editörü: Kani Işık, Akdeniz Üniversitesi, Palme Yayıncılık.

Hayta, Ş., Polat, R., Selvi, S. (2014). Traditional uses of medicinal plants in Elazı ̆̆ (Turkey). Journal of Ethnopharmacology, Cilt 154, pp. 613-623.

Hennekens, S. M. ve Joop H.J.S. (2001) TURBOVEG, a comprehensive data base management system for vegetation data. Journal of vegetation science 12: 589-591.

Heinrich, M., Barnes, J., Gibbons, S., Williamson, E.M. (2004). Fundementals of Pharmacognosy and Phytotherapy, Churchill Livingstone, Edinburgh.

Kadıoğlu, Z., Cukadar, K., Kalkan, N.N., Vurgun, H., Kaya, Ö. (2020). Wild Edible Plant Species Used in the Ağrı Province, Eastern Turkey, Anales del Jardín Botánico de Madrid, Vol 77, No 2. 
Karakaya, S., Polat, A., Aksakal, Ö., Sümbüllü, Y.Z., İncekara, Ü. (2019). An Ethnobotanical Investigation on Medicinal Plants in South of Erzurum (Turkey), Ethnobotany Research and Applications, 18:13, 1-18.

Karakaya, S., Polat, A., Aksakal, Ö., Sümbüllü, Y.Z., İncekara, Ü. (2020). Ethnobotanical Study of Medicinal Plants in Aziziye District (Erzurum, Turkey), Turk J Pharm Sci, 17 (2): 211-220.

Kaval, İ. (2011). Geçitli (Hakkari) ve Çevresinin Etnobotanik Özellikleri. Van: Yüzüncü Yıl Üniversitesi Fen Bilimleri Enstitüsü.

Kaval, İ., Behçet, L., Çakılcıoğlu, U. (2014). Ethnobotanical study on medicinal plants in Geçitli and its surrounding (Hakkari-Turkey). Journal of Ethnopharmacology, Cilt 155, pp. 171-184.

Kaval, İ., Behçet, L., Çakılcıŏglu, U. (2015). Survey of Wild Food Plants for Human Consumption in Geçitli, Hakkari, Turkey. Indian Journal of Traditional Knowledge, 14(2), pp. 183-190.

Kendir, G., Güvenç, A. (2010). Etnobotanik ve Türkiye'de Yapılmış Etnobotanik Çalışmalara Genel Bir Bakış, Hacettepe Üniversitesi Eczacılık Fakültesi Dergisi, Cilt 30, Sayı 1, ss. 49-80, Ankara.

Khatun, S., Uruç Parlak, K., Polat, R., Çakılcıoğlu, U. (2012). The Endemic and Rare Plants of Maden (Elazı̆g) and Their Uses in Traditional Medicine, Journal of Herbal Medicine, Volume 2, Issue 3, 68-75.

Kılıç, Ö. (2016). An Ethnobotanical Survey From Bingöl (Turkey), RA Journal of Applied Research, Volume 2, Issue 10, 685-691.

Kılıç, Ö., Bağcı, E. (2013). An Ethnobotanical Survey of Some Medicinal Plants in Keban (Elazığ-Turkey), Journal of Medicinal Plants Research, Vol. 7(23), pp. 1675-1684.

Kolaç, T. (2018). Konak (Malatya) Yöresi Halk İlaçları, İnönü Üniversitesi, Sağlı Bilimleri Enstitüsü, Yüksek Lisans Tezi, 203s.

Konczak, I., Dalar, A., Konczak-Islam, A.K. (2014). Health Attributes, Antioxidant Properties and Phytochemical Composition of Traditional Medicinal Plants from Eastern Anatolia, In book: Medicinal Plants: Antioxidant Properties, Traditional Uses and Conservation Strategies, Publisher: Nova Science Publishers.

Korkmaz, M., İlhan, V. (2015). Distribution, Traditional Use and Conservation of Geophyte Plants Growing Around Keşiş Mountain, Eastern Anatolia, Turkey, International Journal of Scientific Research in Knowledge, 3(7), pp. 187-197.

Korkmaz, E. (2018). Bahçesaray (Müküs) ve Çevresinin Etnobotanik Özellikleri ve Dijital Ortama Aktarımı. Van : Van Yüzüncü Y1l Üniversitesi Eğitim Bilimleri Enstitüsü.

Korkmaz, M., Alpaslan, Z., Turgut, N., İlhan, V. (2014). Ethnobotanical Aspects of Some Geophytes from Ergan Mountain, Turkey. Bangladesh Journal of Botany , 43(3), pp. 315-321.

Korkmaz, M., Karakuş, S. (2015). Traditional Uses of Medicinal Plants of Üzümlü District, Erzincan, Turkey. Pakistan Journal of Botany, 47(1), pp. 125-134.

Korkmaz, M., Karakuş, S., Özçelik, H., Selvi, S. (2016). An ethnobotanical study on medicinal plants in Erzincan, Turkey. Indian Journal of Traditional Knowledge, 15(2), pp. 192-202.

Korkmaz, M., Karakuş, S., Selvi, S., Çakılcıoğlu, U. (2016). Traditional knowledge on wild plants in Üzümlü (Erzincan-Turkey). Indian Journal of Traditional Knowledge, 15(4), pp. 538-545.

Leto, C., Tuttulomondo, T., Bella, S., Licata, M. (2012). "Ethnobotanical study in the Madonie Regional Park (Central Sicily, Italy) - Medicinal use of wild shrub and herbaceous plant species". Journal of Ethnopharmacology 146: 90-112.

Macit, M. G., Köse, Y. B. (2015). Medicinal plants used for folk medicine in Oltu (Erzurum/Turkey). Biological Diversity and Conservation, 8(2), pp. 74-80.

Mükemre, M. (2013). Konalga, Sırmalı, Dokuzdam Köyleri (Çatak-Van) ve Çevrelerinin Etnobotanik Özellikleri. Van: Yüzüncü Yıl Üniversitesi Fen Bilimleri Enstitüsü.

Mükemre, M., Behçet, L., Çakıllcıŏlu, U. (2015). Ethnobotanical study on medicinal plants in villages of Çatak (Van-Turkey). Journal of Ethnopharmacology, Cilt 166, pp. 361-374. 
Mükemre, M., Behçet, L., Çakılcığlu, U. (2016). Survey of wild food plants for human consumption in villages of Çatak (Van-Turkey). Indian Journal of Traditional Knowledge, 15(2), pp. 183-191.

Nadiroğlu, M. (2017). Karlıva (Bingöl) İlçesinin Etnobotanik Özellikleri, Bingöl Üniversitesi, Fen Bilimleri Enstitüsü, Yüksek Lisans Tezi, 227 s.

Nadiroğlu, M., Behçet, L. (2018). Traditional Food Uses of Wild Plants Among the Karlıva (Bingöl-Turkey), International Journal of Nature and Life Sciences, Cilt 2, Sayı 2, 57 - 71.

Nadiroğlu, M., Behçet, L., Çakılcıŏ̆lu, U. (2019). An ethnobotanical survey of medicinal plants in Karlıova (Bingöl-Turkey). Indian Journal of Traditional Knowledge, 18(1), pp. 76-87.

Olgun, Ş. (2019). Arıcak (Elazığ) İlçesinin Etnobotanik Özellikleri. Bingöl: T.C. Bingöl Üniversitesi Fen Bilimleri Enstitüsü.

Özgen, U., Kaya, Y., Coşkun, M. (2004). Ethnobotanical Studies in the Villages of the District of Ilıca (Province Erzurum), Turkey. Economic Botany, 58(4), pp. 691-696.

Polat, R., Selvi, S., Çakılcığlu, U., Açar, M. (2012). Investigations of Ethnobotanical Aspect of Wild Plants Sold in Bingöl (Turkey) Local Markets, Biological Diversity and Conservation, 5/3, 155-161.

Polat, R., Çakılcı̆̆glu, U., Ertuğ, F., Satıl, F. (2012). An Evaluation of Ethnobotanical Studies in Eastern Anatolia, Biological Diversity and Conservation, 5/2, 23-40.

Polat, R., Çakılcığlu, U., Satıl, F. (2013). Traditional uses of medicinal plants in Solhan (Bingöl- Turkey). Journal of Ethnopharmacology, pp. 951-963.

Polat, R., Çakılcığlu, U., Ulusan, M. D., Paksoy, M. Y. (2015). Survey of wild food plants for human consumption in Elazığ (Turkey). Indian Journal of Traditional Knowledge, 1(1), pp. 69-75.

Polat, R., Güner, B., Yüce Babacan, E., Çakılcıoğlu, U. (2017). Survey of wild food plants for human consumption in Bingöl (Turkey). Indian Journal of Traditional Knowledge, 16(3), pp. 378-384.

Polat, R. (2019). Ethnobotanical study on medicinal plants in Bingöl (City center) (Turkey). Journal of Herbal Medicine, Cilt 16.

Polunin, O. (1969). Flowers of Europe. New York, Toronto: Oxford University Press.

Sõukand, R. ve Raivo, K. (2010). "Herbal landscape: the perception of landscape as a source of medicinal plants". Trames: A Journal of the Humanities and Social Sciences 14: 207.

Sırrı, M., Sırrı, G. (2020). Hakkari İlinde Gıda Olarak Tüketilen Yabani Bitki ve Yabancı Ot Türlerinin Güncel Durumu, Avrupa Bilim ve Teknoloji Dergisi, Sayı 19, 393-409.

Şengün, M.T., Boyraz, Z. (2008). Doğu ve Güney Doğu Anadolu Bölgesinin Doğal Ortam Özelliklerinin Terör Faaliyetleri ve Güvenliği Açısından Değerlendirilmesi, Doğu Coğrafya Dergisi, Cilt 13 , Sayı 20, Sayfalar 267 278.

Tekin, S. (2011). Üzümlü (Erzincan) İlçesinin Etnobotanik Özellikleri. Erzincan: Erzincan Üniversitesi Fen Bilimleri Enstitüsü.

Tetik, F. (2011). Malatya İlinin Etnobotanik Değeri Olan Bitkileri Üzerine Bir Araştırma. Malatya: Fırat Üniversitesi Fen bilimleri Enstitüsü.

Tetik, F., Civelek, Ş., Çakılcığlu, U. (2013). Traditional uses of some medicinal plants in Malatya (Turkey). Journal of Ethnopharmacology, Cilt 146, pp. 331-346.

Tichý, L. ve Jason H. (2006). JUICE program for management, analysis and classification of ecological data. Czech Republic, Brno: Vegetation Science Group, Masaryk University,

Tütenocaklı, T. (2002). Ayvacık (B1, Çanakkale) ve Çevresinin Etnobotaniği, Yüksek Lisans Tezi, Çanakkale Onsekiz Mart Üniversitesi Fen Bilimleri Enstitüsü, Çanakkale. 
Yeşil, Y., Akalın, E. (2009). The Plants of Using for Dye in Kürecik (Akçadağ/Malatya), Eastern Anatolia of Turkey, İstanbul Üniversitesi Eczacılık Fakültesi Dergisi, Cilt 40, 117-124.

Yeşil, Y., Akalın, E. (2016). Fodder, veterinary and miscellaneous useful plants in Kürecik (Malatya- Eastern Turkey). İstanbul Eczazcılık Fakültesi Dergisi, 46(1), pp. 23-27.

Yıldırım, B., Terzioğlu, Ö., Özgökçe, F., Türközü, D. (2008). Ethnobotanical and Pharmacological Uses of Some Plants in the Districts of Karpuzalan and Adiguzel (Van-Turkey). Journal of Animal and Veterinary Advances, 7(7), pp. 873-878.

Ulusal Tez Merkezi: 10 Aralık 2020. <https://tez.yok.gov.tr/UlusalTezMerkezi/>

Türkiye Bitkileri: 20 Ocak 2021 <www.turkiyebitkileri.org $\geq$

TR Dizin: 10 Aralık 2020. <https://trdizin.gov.tr/en/home/>

ISI Web of Knowledge: 10 Aralık 2020. <https://login.webofknowledge.com/>

TUBIVES: “Turkish Plants Data Service” 20 Mart 2021.<http://www.tubives.com/> 